\title{
EDITORIAL
}

\section{The Necessity to Change}

Three major actuarial events took place at the last AFIR Colloquium, in Maastricht:

- A ceremony was held to present the first "Bob Alting von Geusau" Prize, awarded for the best paper on an AFIR subject published in the ASTIN Bulletin during 2001 and 2002. The prize was awarded to Dr Shaun Wang for his paper entitled "A Universal Framework for Pricing Insurance and Financial Risks",

- We heard a rather disturbing speech delivered by Luc HENRARD, Chief Risk Officer at FORTIS, on Risk Management

- Finally we devoted some time to discuss the future of AFIR.

These three events are very strongly intricate.

AFIR is the section that assembled actuaries mainly involved in Finance and Banking. Its primary aim was the development of an actuarial approach of financial risks. From the very start, and over the years, the subjects dealt at AFIR are more and more oriented towards the new Theory of Finance (I mean by this, stochastic processes, the no arbitrage valuation paradigm, ALM studies based on stochastic simulations and so on). Just a few of AFIR founders continue to promote a different and so to speak actuarial approach for financial risks. But clearly the papers written by AFIR actuaries are more and more filled with the new financial paradigm. Like the financial engineers, AFIR actuaries are using the tools and methodologies developed by the mathematical economists. Therefore it was not so surprising that the jury of the AFIR Prize had decided to recognize the talent of Dr Wang who succeeded in his paper - and in a subsequent one also published in ASTIN Bulletin - to close the gap between insurance and finance by proposing a common framework for the evaluation of risks.

In the same way, the Maastricht AFIR Colloquium was certainly the right place and the right time to deliver a speech on Risk management in financial conglomerates. Conglomerates integrate lines of business exposing the company to risks of different nature. These risks are today evaluated and managed separately and differently by actuaries and financial engineers. But regulators, rating agencies, top management, board of directors and shareholders require that a common approach be developed to measure and manage risk and capital.

So our guest speaker urged the actuaries to meet the new exciting challenge of proposing a common risk measurement framework. And he pointed out, about that, the pressing necessity to change the academic actuarial curriculum. 
Finally spurred by a few Dutch actuaries we undertook a review of the strengths and weaknesses of AFIR and launched an exploratory reflection about its future.

AFIR is playing a dual role:

- In traditional areas (insurance, pensions, etc.) by adding to the actuarial knowledge the financial expertise and developing financial risk management,

- In non-traditional areas (portfolio management, banking, etc.) by developing new skills and specializations for actuaries and implementing risk management techniques.

So to speak, the AFIR actuary is an expert in ALM, in asset management, in Banking. Further fields of natural development could be in the measurement and management of risks faced by other industries.

Anyway, because its expertise covers all the types of risks, the AFIR actuary is certainly one of the most appropriate persons to become risk officer in the financial industry. During the discussion, it came out that AFIR is definitely perfectly suited to become the platform for actuaries involved in global risk management.

The concomitance of these events is revealing. We actuaries are not alone in the world.

We are discovering that other people are also dealing with risks. Many years ago the concept of risk has been introduced in the theory of portfolio leading to the emergence of a new race of risk specialists, the financial engineer. $\mathrm{He}$ or she is able to mix applied mathematics and financial economics and develop a rational approach for modeling financial contracts by applying microeconomics concepts such as the no arbitrage opportunities rule and by introducing the notion of the price of risk. And now the International Accounting Standard Board is willing to impose new accounting standards that are directly in the continuation of these concepts. New developments in insurance solvency measurement are also inspired by some of the concepts, like the VAR, implemented in banking regulations.

Obviously, we have missed a first opportunity to become key players in this field, although some of the most prominent actuaries like Hans Bühlmann had led the way as early as in 1980. But Debreu, Arrow, Black, Scholes, Merton, Lucas etc. are not actuaries, and their work is not very popular among actuaries.

Shall we miss the boat again? Don't we have to assert our capacity to become global risk specialists provided that we are able to integrate these new processes and to incorporate into our profession some of our fellow financial engineers?

What makes us so different from financial engineers?

The financial engineer is almost obliged to develop a complete theory of pricing that will explain the formation of prices and be accepted by all market participants. In the financial world, the existence of a market for traded assets is closely dependent on the exchange of information based on a common evaluation framework.

The actuary, for his part, is not interested in developing a theory of rational pricing but better want to find the best way to measure risk, to price a 
contingent claim by reference to a distribution of losses, adding a loading factor to cover the non measurable. This difference in methodology may be due to the fact that there is no market of traded insurance liabilities and therefore no need of a common explanatory model.

Another way of coping with risk distinguishes, also, our approaches. In finance, hedging is the only way to suppress the risk of a position, and it will have to be managed permanently. In insurance, adding a prudent loading factor to the expected value will be the most common technique used to cover risks and will not necessitate a frequent adjustment.

It is now time to overcome these differences. Let's try to build a common roof. The actuary cannot ignore the theory underlying the valuation principles and the reality of the fair value principle; the financial engineer should incorporate the prudence principle and recognize that the fair value of liabilities cannot be evaluated exactly in the same way as the fair value of assets.

This should lead us to change the actuarial curriculum to put it more in line with the current needs in terms of risk management.

In changing the actuarial curriculum it is clear that we will have to face the problem of the duration of actuarial studies. If we want that the young actuary be able to be at the same time a good specialist in life and non-life, pensions, asset management, banking, risk management etc...we will have to increase dramatically the hours of studies.

It may be the time to change our traditional educational model and to take into account the necessity to complete the curriculum by adding, after specialization, a common body of knowledge in risk measurement and management. We will have to take into account the difference between the actuarial education given to insurance and pensions actuaries, the financial education given to financial engineers and more generally the education given to applied mathematicians and statisticians. To each of these people, one or more bricks of knowledge will be missing. For some it will be the financial approach, for others the actuarial approach. So some bricks will have to be added to the construction in order to give to everybody the same core knowledge and skills that have to be shared by all future risk specialists. On top of this we should provide the students with the latest theories and methods in risk measurement and management, covering all the aspects of this new science from the taxonomy of risks to the theory of regulation. This could be the aim of an International Risk Institute devoted to education and research.

Jean BERTHON Chairman of AFIR

\section{Editorial Note}

In ASTIN Bulletin 33.2 we omitted to name the author of the editorial. This was written by our Co-Editor, John Ryan. 